\title{
对话姚檀妳：走近第二次青藏高原综合科学考察
}

张冬梅, 张莉

\section{Tandong Yao: The Second Tibetan Plateau Scientific Expedition and Research}

Dongmei Zhang \& Li Zhang

doi: 10.1360/TB-2019-0267

青藏高原是中国最大、世界海拔最高的高原. 作为地 球上最独特的地质-地理-生态单元, 是我国重要的生态安 全屏障、战略资源储备基地, 是中华民族特色文化的重要 保护地. 2017年8月 19 日, 在拉萨启动了第二次青藏高原综 合科学考察研究(简称第二次青藏科考)国家专项. 系统开 展第二次青藏科考, 将为“守护好世界上最后一方净土”、 “建设美丽的青藏高原”和绿色丝绸之路建设提供重要科技 支撑. 到2019年9月, 第二次青藏科考已历时两年多, 陆续 取得了一批重要的成果. 为进一步了解第二次青藏科考和 此领域相关研究, 《科学通报》对话第二次青藏科考队队 长、中国科学院院士、中国科学院青藏高原研究所姚檀栋 研究员, 分享他的工作以及不同寻常的经历和用实践积累 的宝贵经验. 姚檀栋从事冰川与环境变化和地球系统科学 研究. 相关研究成果在Nature, Science, Nat Clim Change, Nat Geosci, Rev Geophys, Proc Natl Acad Sci USA, Bull Amer Meteorol Soc, J Geophys Res等杂志发表. 他在青藏高 原冰川与环境变化方面的研究成果, 不仅为科学发展做出 了贡献，而且为社会经济发展做出了贡献.

《科学通报》: 2017年我国开始了第二次青藏科考, 作为科考队队长您可否介绍一下本次科考的目标、任务 和特点?

姚檀栋: 从第一次青藏科考开始, 距今已近 50 年. 这 50 年来, 青藏高原自然与社会环境发生了巨大变化. 最大 的变化是气候变暖, 这一地区的气候变暖幅度是同期中国 东部和全球平均值的 2 倍, 因此是全球变暖背景下环境变 化不确定性最大的地区. 与此密切相关的变化是青藏高原 水循环和生态及生物多样性的重大变化. 冰川退缩、冻土 退化、冰湖溃决、草地退化等对人类生存环境和经济社会 发展造成了重大影响. 冰崩作为一种新出现的与气候变暖 密切相关巨灾过程, 影响更为严重. 2016年7和9月, 在西 藏阿里地区阿汝错湖区发生了两次非常严重的冰崩灾害, 给当地人民的生命和财产安全造成了非常大的损失, 这是 以前没有发生过的现象. 2018年10月, 在雅鲁藏布江大拐 弯发生了次冰崩堵江事件, 形成堰塞湖, 导致上游水位上

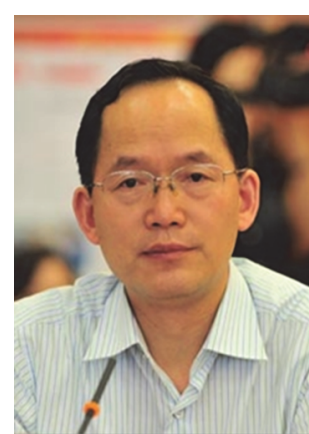

中国科学院院士 姚檀栋

涨，对当地和下游区域居民生命财产安全造成极大的威 胁. 青藏高原环境变化的影响将是广域甚至全球的. 目前 大家特别关注这种不确定性对“一带一路”沿线几十个国家 和 30 多亿人口的生存与发展带来的环境挑战. 因此, 考察 研究过去 50 年来环境变化和影响并提出应对方案, 既是科 学发展的需求, 也是社会发展需求.

在这种背景下，中国科学院(中科院)和西藏自治区共 同推动发起第二次青藏科考. 2017年8月 19 日在拉萨召开 了第二次青藏科考启动仪式. 习近平总书记发来贺信, 时 任国务院副总理刘延东同志出席启动仪式并宣读了习总 书记给中科院科考队的贺信. 习总书记在贺信中指出，“青 藏高原是世界屋脊、亚洲水塔, 是地球第三极, 是我国重 要的生态安全屏障、战略资源储备基地, 是中华民族特色 文化的重要保护地. 这次科学考察研究要聚焦水、生态、 人类活动等, 揭示青藏高原环境变化机理, 优化生态安全 屏障体系，建设美丽幸福的青藏高原，同时要推动青藏高 原可持续发展、推进国家生态文明建设、促进全球生态环 境保护”. 党和国家领导人对第二次青藏科考提出的要求, 使得第二次青藏科考成为国家大事. 在国务院的直接领导 下，在科技部、中科院、西藏自治区、青海省等多方力量 的协调下，第二次青藏科考国家行动的大幕正式拉开.

第二次青藏科考将重点考察研究过去 50 年来青藏高原 环境变化的过程与机制及其对人类社会的影响，提出应对 
“亚洲水塔”变化与影响、优化青藏高原生态安全屏障体系、 建设国家战略资源储备基地、引领全球生态环境保护的科 学方案. 第二次青藏科考有 10 大任务, 包括西风-季风协同 作用及其影响、“亚洲水塔”动态变化与影响、生态系统与 生态安全、生态安全屏障功能与优化体系、生物多样性保 护与可持续利用、人类活动与生存环境安全、高原生长与 演化、资源能源现状与远景评估、地质环境与灾害、区域 绿色发展途径. 10大任务共设计了60多个科考专题. 每个 任务根据自己的目标和特点, 领导所属专题开展考察研 究. 整个科学考察研究将在包括“亚洲水塔”区、喜马拉雅 区、横断山高山峡谷区、祁连山-阿尔金区、天山-帕米尔 区5大综合考察研究区的19个关键区展开.

第二次青藏科考将通过高寒网、青藏高原数据中心、 “第三极环境(TPE)”国际中心及其旗舰站和中科院海外科 教中心等国际科学联盟, 结合卫星遥感、系留浮空艇、无 人机等新技术, 获取大范围、多尺度、系统化、标准化的 精准数据. 第二次青藏科考还将通过建设科考综合基地和 示范工程基地, 针对气候变暖影响下典型自然灾害链重灾 易发点, 开展监测预警和调控, 产出“用得上、有影响、留得 下”的科考成果, 长效支撑青藏高原地区生态环境保护和 绿色可持续发展.

第二次青藏科考也将充分利用以我为主的TPE国际计 划, 加强和国际伙伴机构及国际科学联盟顶尖科学家的合 作, 引领第三极地球系统科学研究, 同时将推动泛第三极 和三极环境的研究.

《科学通报》: 您曾担任中科院青藏高原研究所所长, 还是中科院青藏高原地球科学卓越创新中心的主任和首 席科学家. 从普通研究人员, 到研究团队的核心, 再到 科学计划领导者, 您是如何调整自己角色的转变? 您又 是如何在这个过程中协调多单位、多学科研究人员的积 极协作、高效、出色地完成工作的?

姚檀栋: 我是一名科学家, 进行科学研究是兴趣驱动, 也是我的本源. 我曾是中科院青藏高原研究所所长. 作为 一名有责任心的科学家, 服从组织的决定, 进行新的科学 发展所需要的科研机构建设, 是应有的担当. 至于科学研 究团队的组建, 是一个从小我到大我再到小我的哲学逻 辑: 当在实验室组建科研小组时, 有一个围绕国际科学研 究前沿方向的7 8人核心骨干小组, 就可以干一件事情了; 当在研究所组建团队的时候, 就需要从国际科学前沿推动 若干领域的众多核心科学小组的建设, 组成若干科研团 队, 这样才能保证研究所做成推动青藏高原研究整体发展 的大事; 当在全国层面组建像第二次青藏科考这样规模的 人才集群建设的时候, 就需要把最优秀的研究团队联合到 一起, 这样才能推动青藏事业的发展. 不管是在一个核心 骨干小组, 还是在一个研究团队或者在一个研究集群, 科 学组织者一定是科学践行者. 这是国际科学发展的成功理
念和模式. 用这种理念和模式, 我们出色完成了中科院 $\mathrm{B}$ 类先导青藏专项. 用这种理念和模式, 我们将继续推动第 二次青藏科考.

《科学通报》: 与其他学科不同, 地学研究需要长时 间的实地调查, 能和我们分享一下您自己是如何一步一 步、坚持不解, 取得今天的成就并获得维加奖的吗?

姚檀栋: 我的冰川学研究最早是从冰川变化和冰川物 质平衡研究开始的. 20 世纪 80 年代以后, 国际上已经关注 到气候变化研究的重要性, 冰芯研究成为高分辨率研究过 去气候变化的重要途径. 因此我选择到当时国际冰芯研究 的最权威机构法国冰川与环境地球物理研究所做博士后 研究, 在那里我接触到了当时进行南极冰芯研究最前沿的 科学研究团队和最顶尖的冰芯科学家Claud Lorius和Jean Jouzel. 与此同时, 美国的Lonnie Thompson教授的研究团 队开拓了山地冰芯研究的新领域. 我在法国完成博士后研 究以后, 就直接从法国申请去Thompson教授的冰芯实验 室进行山地冰芯博士后研究. 在美国期间, 我和Thompson 教授深人讨论了在青藏高原开展冰芯研究的重要性和可 能钻取冰芯的地方, 并提出了研究方案. 1990年回国以后, 我们全力以赴开始了青藏高原冰芯研究的征程. 我们先后 在祁连山敦德冰帽、西昆仑山古里雅冰帽、喜马拉雅山达 索普冰川、高原腹地的普若岗日冰原、藏色岗日冰帽等地 钻取了一系列冰芯. 我们钻取的古里雅冰芯, 是全球中低 纬度迄今最深的冰芯, 也是除南北极以外唯一能够提供末 次冰期冰盛期以来气候环境记录的冰芯. 我们在达索普冰 川海拔 $7200 \mathrm{~m}$ 处钻取的冰芯, 是全球海拔最高的冰芯, 很 好地记录了这一地区过去千年以来季节到年际尺度高分 辨率的气候环境变化信息. 后来, 我的研究方向从冰芯逐 渐到冰芯中古气候记录参数的现代过程研究, 特别是氢氧 稳定同位素现代过程研究, 这就和水汽输送过程密切联系 到了一起. 进人 21 世纪, 地球系统科学研究兴起, 青藏高 原作为地球上地球系统多圈同时存在并相互强烈作用的 典型地区, 冰冻圈和水循环过程与影响成为这一地区最受 关注的科学问题. 冰川变化和冰川物质平衡、冰川-湖泊相 互作用、季风与西风协同作用都要从水循环过程的角度去 理解, 我们的研究思路也进一步提升到地球系统科学和多 圈层相互作用研究的角度, 开展青藏高原环境变化研究. 我们这一代科学家很幸运, 赶上了一个和平巨变的时代. 这个巨变对进行青藏高原的科技人员来说，就是现在我们 的野外科考装备更好了, 野外科考后勤保障能力更强了, 野外科考手段更先进了. 浮空艇、无人机、无人船、遥感 飞机、冰上机器人等新技术、新手段、新方法将会大量应 用于第二次青藏科考, 这将大大提高野外科考效率，但更 重要的是将通过新技术的应用, 提高我们的科考能力, 实 现科学认识的新突破. 第二次青藏科考的“三新”技术应用 以及科考效率和科考能力的提升, 是第一次青藏科考时所 
无法想象的.

《科学通报》: 珠穆朗玛峰、喜马拉雅山、昆仑山、 喀喇昆仑山...…这些在人们看来神秘又遥不可及的地 方, 就是您实际考察工作的场所, 风餐露宿是家常便饭, 甚至要冒生命危险. 要在最不适合人类生存的地方, 揭 开自然的奥秘, 能否和我们分享一下您如何与青藏高原 结缘和关于那里的难忘经历吗?

姚檀栋: 我是做冰川和气候环境变化研究的. 说到和 冰川结缘, 要追溯到我的大学时代. 1978年, 兰州大学安 排了我作为学生代表和教师代表张林源教授参加了当时 的“长江流域规划办公室”组织的长江源头考察, 我们承担 冰川变化考察研究任务, 恢宏壮阔的高原景观和䇯人云天 的冰川雄姿震撼了我, 也深深吸引了我. 后来在美国和法 国进行了阿拉斯加和阿尔卑斯冰川变化考察研究, 每一次 的冰川之行都会在我脑海里根植下更深的信念—我爱冰 川! 20世纪80年代, 我从冰川变化研究进人冰芯记录研究. 在高山之巅钻取冰芯, 条件自然是很艰苦的, 但是也拥有 了欣赏绝佳冰川美景和地球雄姿的机会. 1997年我们在达 索普冰川7200 $\mathrm{m}$ 的海拔钻取冰芯, 晚上吃饭前大家聚在帐 篷门口, 朝东看已经是满天繁星, 朝西看仍然夕阳余光反 补下的山色湖光, 恍惚就是天上人间的瞬间切换. 从我们 帐篷所在的达索普冰川垭口走下去就是尼泊尔首都加德 满都, 有队员就开玩笑说, 我们吃完晚饭出一趟国吧. 兴 趣就是科学的恋人. 您可以想象, 当全世界的登山爱好者 冒着生命危险, 排着长队等候 3 个小时登珠穆朗玛峰, 仅 仅是为了一览众山小的超级体验的话, 我们不但实地感受 了这种超级体验, 更重要的是通过这种超级体验探索科学 的奥秘, 这是一种完美的结合! 我作博士生的导师施雅风 先生曾经说过, “冰川研究是一项豪迈的事业, 是勇敢者的 事业!”我在美国作博士后的合作导师Thompson教授今年 72 岁, 仍然在海拔5000多米的高度钻取冰芯! 对大自然的 热爱, 对科学的着迷, 科学巨匠们的所言是他们发自内心 深处的热爱自然的科学表白, 科学巨匠们的所行是超出常 人想象的、热爱自然的科学行动. 我所经历和所感受的这 些人和事都永远难忘.

《科学通报》: 青藏高原作为气候变化的敏感地带, 近年来有很多团队开展相关研究, 可否谈谈您所在团队 做了哪些工作?

姚檀栋: 在过去几年里, 我的团队主要工作是集中在 青藏高原地表多圈层相互作用的两个方面:

第一, 通过水体稳定同位素的研究揭示了印度季风与 西风协同作用在青藏高原的 3 种模态. 我们以青藏高原 24 个站点长达 10 年的降水稳定同位素观测结果为基础, 结合 目前最先进的高分辨率稳定同位素大气环流模型的模拟 结果和现代气象观测数据, 认识到西风和印度季风对青藏 高原降水稳定同位素的影响表现为 3 种模态, 即印度季风
模态、西风模态和过渡模态. 西风模态表现为降水氧稳定 同位素与气温具有相同的季节变化模式, 即夏季高值, 冬 季低值. 印度季风模态表现为降水氧稳定同位素在春季达 到最高值, 夏季达到最低值. 过渡模态由于地处西风和印 度季风影响交汇区，降水氧稳定同位素没有明显的季节性 极值, 当区域受单一主导大气环流控制时, 温度效应相对 更显著. 在此认识的基础上，为了更深人地认知西风-季风 传输水汽与局地对流水汽对区域水循环的贡献, 我们推动 了青藏高原水汽稳定同位素观测体系的建立. 目前已建成 了全球同类最大的、首个青藏高原大气水汽稳定同位素三 维观测体系, 包括西风-季风主要传输路径上的 9 个地表连 续观测站点和实现地表至 $3000 \mathrm{~m}$ 高空原位连续观测的浮 空艇科学观测平台. 在此体系下开展的系统而长期的观测 将为青藏高原水汽传输过程研究和亚洲水塔水量变化研 究提供关键科学数据.

第二，揭示了西风与季风相互作用对现代冰川和湖泊 的影响. 我们综合分析了青藏高原地区7个代表性区域内 7000 多条冰川过去 30 年的遥感面积变化, 同时结合 82 条冰 川的末端变化及 15 条典型冰川的物质平衡实地观测数据研 究. 结果显示: 受印度季风影响的喜马拉雅山脉及青藏高 原东南部呈现最强烈冰川萎缩, 其特点是冰川末端强烈退 缩、冰川面积急剧缩小、冰川物质平衡呈强烈负平衡. 冰川 萎缩程度从喜马拉雅山向西风季风相互作用过渡的高原内 部递减, 在西风控制的帕米尔高原萎缩程度最小, 其特点 是冰川长度退缩较少、冰川面积减少幅度较小、冰川物质呈 微弱正平衡. 青藏高原冰川呈现20世纪90年代以来加速亏 损的趋势. 结合卫星图像和实地调查，我们证实1976 1999 年青藏高原内陆封闭湖泊变化的多样性，但1999 2010年这 些湖泊的面积和深度均明显增大. 1999 2010年湖面面积平 均增长率是1990 1999年的3倍. 青藏高原内陆湖泊和喜马 拉雅山地区湖泊呈现近期南北反相变化状态: 印度季风影 响下的高原南部雅鲁藏布江流域湖泊面积普遍缩减, 而西 风控制区的北部差塘高原湖泊普遍强烈扩张.

《科学通报》: 青藏高原的冰川孕育着亚洲几大河 流, 据说已有超过 $80 \%$ 的冰川在退缩, 这会对我们造成 什么样的影响? 可否谈一下目前我国对改善青藏高原的 生态环境做了哪些工作?

姚檀栋：青藏高原上发育有全球中低纬度最多的冰 川, 是亚洲主要大江大河的发源地, 学术界也因此通常称 青藏高原是 “亚洲水塔”。在目前的全球气候背景下, 青藏 高原冰川整体呈现出退缩的态势, 但是存在明显的空间差 异. 我们的研究发现, 在高原南部喜马拉雅山、藏东南一 带, 这些地区的冰川受到印度季风的影响. 但是近几十年 来印度季风带来的降水减少了, 而冰川上同时期气温又升 高了, 这样的格局导致了这些地区冰川在过去几十年里强 烈退缩, 表现为冰川长度减少, 冰川面积减小, 冰川厚度 
减薄等. 但是往高原内部, 比如唐古拉山、芫塘高原一带, 印度季风的影响就比较弱了, 这些地区冰川退缩的幅度就 比南部地区小很多. 到了高原北部, 尤其是高原西北部的 昆仑山、喀喇昆仑山、帕米尔高原这一带, 基本不受印度 季风的影响, 这些地区的降水主要是西风环流从大西洋、 北冰洋和地中海携带过来. 在过去几十年, 这些地区降水 是增加的, 虽然气温也同样在升高, 但是这些地区的冰川 退缩就很微弱, 像西昆仑-喀喇昆仑一带, 大部分冰川是比 较稳定的, 部分冰川甚至是前进的, 出现了学术界热烈讨 论的“喀喇昆仑异常”现象.

冰川退缩的影响, 最直接的体现是在冰川下游的湖泊. 我们的研究发现, 过去几十年来, 高原上主要靠冰川融水 补给的湖泊都呈现出了湖泊面积扩张的态势. 近期青藏高 原湖泊数量的增多和面积的增大是十分明显的, $80 \%$ 以上 的湖泊在扩张. 像高原内部的色林错, 以前是西藏第二大 湖, 但近几十年大量冰川融水汇人使得湖面快速扩张, 现 在已经超过纳木错成为了西藏最大的湖泊. 但是湖泊扩张 就会淹没周边的草场湿地, 使得高原的农牧业受到影响. 另一方面, 冰川退缩也会造成下游地区冰湖溃决等灾害风 险增加.

保护青藏高原环境一直都是我国环境保护基本国策的 重中之重. 早在20世纪60年代, 青藏高原地区就开始启动 国家级自然保护区建设; 1978年以后, 相继实施了一系列 生态建设与环境保护工程；2009年国务院常务会议审议并 通过的《西藏生态安全屏障保护与建设规划》和《青海三 江源自然保护区生态保护与建设工程》, 集中体现了努力 构建青藏高原生态安全屏障体系的国家意志. 2011年国务 院颁发《青藏高原区域生态建设与环境保护规划：2011 2030年》. 保护青藏高原环境是新一届中央领导集体关注 的重点. 习近平总书记强调, “西藏是重要的国家安全屏 障, 也是重要的生态安全屏障、重要的战略资源储备基地、 重要的高原特色农产品基地、重要的中华民族特色文化保 护地、重要的世界旅游目的地, 要保护好世界上最后一方 净土”. 2017年启动的第二次青藏高原综合科学考察研究的 重要目标之一, 就是青藏高原生态环境保护.

《科学通报》: “第三极环境国际计划”受到全世界关 注, 这一研究是从什么时间开始的? 目前进展如何? 您 带领科研团队正在开展青藏高原地球系统相关的研究, 能做一个简单介绍吗?

姚檀栋：关于“第三极”的科学理念实际上早在 20 世纪 就提出了来. 但如何将 “第三极” 作为一面科学的旗帜举起 来, 则不是一件容易的事. 要举起这面旗帜, 需要有全球 关注的前沿科学问题的引导, 需要有可实施的先进科学方 案, 需要有一流国际科学团队的联合, 需要一定规模的研 究经费的支持. 在经过相当时间的酝酿和准备之后, 2009 年所有这些必要条件都基本具备, 这一年“第三极环境国
际计划(简称TPE)”正式启动. 2012年, 中科院启动了战略 性先导科技专项(B类)“青藏高原多圈层相互作用及其资源 环境效应”，进一步强化了对TPE的全方位支持，同时也取 得了具有重要国际影响力的突破性成果：提出了青藏高原 碰撞隆升时空变化的新观点、证实了青藏高原的远程辐散 源效应、发现了西风一季风作用下的链式响应对青藏高原 现代环境的决定性影响. 与这几项突破相关的SCI科学论 文约900篇, 包括20多篇Nature、Science 等国际顶级期刊论 文. 中科院文献情报中心统计近期国际上青藏高原的研究 工作，中国不仅仅在发文量和引用频次上超越了欧美大 国, 在高端杂志发表的论文也赶了上来. 与此同时, 研究 成果的国际影响力也日益剧增. 关于第三极冰川变化的研 究成果进人了汤森路透(现Clarivate Analytics公司)评选出 的 2015 年和 2016 年地学十大前沿领域的第一方阵. 同处在 第一方阵, 大家提出的问题也是相似的: 未来青藏高原研 究的国际前沿方向在哪里? 未来青藏高原研究国际前沿方 向的旗帜是什么? 未来青藏高原研究归集前沿的突破点在 哪里? 这些都需要有新的定位. 从2015年开始, TPE的核 心科学团队就在不断探讨这方面的问题, 大家的认识也在 不断深化. 目前的基本共识是, 地球系统科学是未来 TPE 的领跑方向, 多圈层过程和作用是TPE地球系统研究中的 一面旗帜, 环境变化与影响及其应对是近期TPE研究的科 学突破点. 在这种理念下, 青藏高原就不能作为一个孤立 的地质地理单元来研究, 而是要放在区域甚至全球的大背 景上来研究. 因此, 从2015年以来, TPE的国际顶级专家们 在尼泊尔加德满都、美国哥伦布、瑞士达沃斯、瑞典哥德 堡等地举行的专门讨论会上, 就如何在地球系统科学新高 度开展了广泛而深人的讨论, 提出了从 TPE到PAN-TPE, 从PAN-TPE到TPEC的大科学思路. 相信这一全球科学共 识的新的科学前沿将引导我们走向新的科学突破.

《科学通报》: 您对未来我国地球科学的发展方向有 何展望? 对年轻科研工作者的培养有何建议和期望?

姚檀栋: 21 世纪, 地球科学的发展呈现出向地球系统 科学发展的趋势. 地球系统科学研究要将大气圈、水圈、 冰冻圈、岩石圈、生物圈、人类圈等不同的地球圈层研究 有机整合起来, 揭示各个子系统之间相互联系和相互作用 的机制, 为全球环境变化和可持续发展建立科学基础, 并 为地球系统变化预测和管理提供依据. 地球系统科学研究 的空间范围从地下到地球外层大气空间, 时间尺度从地质 历史时期的数亿年到未来数十年. 我们前期通过中科院 $\mathrm{B}$ 类先导青藏专项在青藏高原地球系统科学研究方面做了 一些初步尝试, 得到了一些重要的成果, 也为以后的研究 奠定了基础. 我们现在推动的第二次青藏高原综合科学考 察研究国家专项和正在实施的中科院A类先导专项“泛第 三极环境变化与绿色丝绸之路建设”研究都是围绕青藏高 原和以青藏高原为核心的泛第三极地区的地球系统科学 
开展研究.

对年轻科研工作者培养这个问题, 我简单谈一谈我对 自己学生的培养. 首先, 兴趣非常重要, 科学研究如果没 有兴趣是很难坚持下去的. 我的硕士生、博士生人学之后, 通常都会让他们先熟悉我所从事的研究领域的最新研究 动态, 从中挑选自己感兴趣的方向, 然后我们再多次交流, 让他们逐步进人角色. 其次, 要坚持、要耐得住寂寞. 我的 学生确定好研究方向后, 就需要自己去查阅相关文献, 熟 悉样品的获取、前处理、实验等流程. 这些过程往往是高 强度的脑力劳动、高强度的体力劳动、重复性的实验流程、 很枯燥的工作环境的交替, 所以需要毅力和忍耐. 有了观 测数据和实验结果, 就要通过讨论提炼正确结论. 我要做 的就是引导他们、调动他们的主观能动性, 使用正确的科 学研究思路和方法, 准确把握学科领域的前沿和热点, 发 现科学问题和解决科学问题. 全身心投人十分重要. 我常 说 8 小时是做不出优秀科研成果的, 要专心投人科研工作 才有可能出好成果. 最后, 要有团队合作精神. 我经常给 学生强调, 地学研究不是单打独斗, 一定是一个团队形成
合力去做事. 想着从别人那里或从这个团队那里去获取什 么的时候，同时要想着自己能够给这个人或这个团队奉献 点什么。

《科学通报》: 作为学术沟通的桥梁, 您认为《科学 通报》应该怎样定位和发展, 从而更好地为科学交流服 务?

姚檀栋: 《科学通报》是国内一份非常优秀的综合性 学术期刊. 我们团队, 包括我本人有很多重要的成果都发 表在《科学通报》上. 现在《科学通报》中英文版分开了, 这个变化很好. 中文版针对国内的读者, 继续保持国内受 众面广的特色; 英文版针对国际读者, 介绍最新创新研究 成果. 这两年《科学通报》英文版改革后上升非常快, 2019 年的影响因子到了 6.277. 《科学通报》应该将扩大国际影 响力作为今后的重点任务, 包括扩大投稿队伍的国际群 体、提高评审人的审稿能力和提高稿件的评审质量. 我相 信《科学通报》会发展得越来越好, 并成为国际上重要的 科学研究交流平台.

\section{推苼阅读文献}

1 Yao T, Xue Y, Chen D, et al. Recent Third Pole's rapid warming accompanies cryospheric melt and water cycle intensification and interactions between monsoon and environment: multi-disciplinary approach with observation, modeling and analysis. Bull Amer Meteorol Soc, 2019, 100: 423-444

2 Gao J, Yao T, Masson-Delmotte V, et al. Collapsing glaciers threaten Asia's water supplies. Nature, 2019, 56: 19-21

3 Yao T D, Xu B Q, Guo Z T, et al. Assessment of environmental change on Tibetan Plateau (in Chinese). 2015 [姚檀栋, 徐柏青, 郭正 堂, 等. 西藏高原环境变化科学评估. 2015]

4 Yao T, Thompson L, Yang W, et al. Different glacier status with atmospheric circulations in Tibetan Plateau and surroundings. Nat Clim Change, 2012, 2: 663-667

5 Yao T, Masson-Delmotte V, Gao J, et al. A review of climatic controls on $\delta^{18} \mathrm{O}$ in precipitation over the Tibetan Plateau: Observations and simulations. Rev Geophys, 2013, 51: 525-548

6 Yao T, Wu F, Ding L, et al. Multispherical interactions and their effects on the Tibetan Plateau's earth system: A review of the recent researches. Natl Sci Rev, 2015, 2: 468-488

7 Xu B Q, Cao J J, Hansen J, et al. Black soot and the survival of Tibetan glaciers. Proc Natl Acad Sci USA, 2009, 106: 22114-22118

8 Kääb A, Leinss S, Gilbert A, et al. Massive collapse of two glaciers in western Tibet in 2016 after surge-like instability. Nat Geosci, 2018, 11: 114-120

9 Piao S, Tan J, Chen A, et al. Leaf onset in the northern hemisphere triggered by daytime temperature. Nat Commun, 2015, 6: 6911

10 Shen M, Piao S, Jeong S J, et al. Evaporative cooling over the Tibetan Plateau induced by vegetation growth. Proc Natl Acad Sci USA, 2015, 112: 9299-9304

11 Liang E, Wang Y, Piao S, et al. Species interactions slow warming-induced upward shifts of treelines on the Tibetan Plateau. Proc Natl Acad Sci USA, 2016, 113: 4380-4385

12 Li X, Jiang L, Meng F, et al. Responses of sequential and hierarchical phenological events to warming and cooling in alpine meadows. Nat Commun, 2016, 7: 12489

13 Zheng H, Clift P D, Wang P, et al. Pre-Miocene birth of the Yangtze River. Proc Natl Acad Sci USA, 2013, 110: 7556-7561

14 Ni X, Li Q, Li L, et al. Oligocene primates from China reveal divergence between African and Asian primate evolution. Science, 2016, 352: $673-677$ 